\title{
Um estudo de usabilidade de sites de empresas virtuais
}

\author{
Simone Bacellar Leal Ferreira \\ UNIRIO. \\ Marie Agnes Chauvel \\ IAG PUC Rio \\ Denis Silva da Silveira \\ IBMEC
}

\begin{abstract}
Resumo
O presente artigo apresenta uma análise dos Requisitos Não Funcionais (RNF) de usabilidade com o objetivo de mostrar como eles podem interferir na qualidade de um site. Esse trabalho se diferencia de anteriores dedicados ao mesmo tema, pois compara uma empresa local, a brasileira "ingresso.com. br", primeira organização estabelecida no Brasil para vendas de ingresso on-line, e uma global, a multinacional "ticketmaster.com.br", uma das líderes mundiais em vendas de ingressos. Esses sites foram escolhidos devido ao fato de o sucesso dessas companhias depender, em boa parte, de suas habilidades em estabelecer e manter uma comunicação com seus clientes. Para efetuar a análise dos sites, foi usada uma taxonomia que descreve, enumera e classifica os requisitos. A contribuição do artigo é a de ressaltar a importância dos RNF de usabilidade, fornecendo um conjunto de características que devem ser levadas em consideração quando se está construindo aplicações comerciais.
\end{abstract}

Palavras-chave

Usabilidade, sistemas de informação baseados na web, empresas virtuais.

\section{Usability of virtual organization's sites}

\begin{abstract}
This paper presents an analytical study of the non-functional requirement (NFR) usability with the objective of showing how they can interfere on the quality of a product. It differs from other articles once it presents an analysis of two sites: the Brazilian "ingresso.com.br", first ticketing company established in Brazil and the multinational "ticketmaster. com.br", one of world's leading ticketing company. These sites were chosen because the success of these companies relies, in part, on its ability to establish and maintain optimal communication with their clients. To perform this analysis, it was used a taxonomy that describes, enumerates and classify the requirements; then it compares the sites to verify which offers better usability.

This paper describes characteristics that should be considered during the design of an e-commerce site, enhancing the importance of the NFR usability.
\end{abstract}

Key words

Usability, web based information systems, virtual companies. 


\section{INTRODUĈ̣̃O}

Com a Internet e as novas tecnologias da informação, surgiu um novo tipo de empresa: a empresa virtual. $\mathrm{Na}$ verdade, a Internet está mudando a forma com que as organizações funcionam e as pessoas trabalham (ALBERTIN, 1999, 2000, 2001).

Empresas virtuais consistem de uma cooperação temporária entre empresas independentes que se unem para satisfazer uma oportunidade de negócio, geralmente com o apoio de tecnologias de informação (http_4). Essas empresas perceberam que a conveniência em se oferecer uma compra on-line podia ser uma grande oportunidade. Para esse tipo de empresa, a informação é essencial. Portanto, ela deve fluir de forma apropriada, em todas as partes da empresa e entre a organização e seus clientes. que atuam no mesmo ramo de atividade, a venda de ingressos pela internet, uma brasileira, o "ingresso.com.br", e outra multinacional, o "ticketmaster.com.br". O propósito da análise é mostrar como a não consideração dos RNF de usabilidade pode interferir na qualidade de um produto e, conseqüentemente, no seu sucesso.

\section{METODOLOGIA}

A pesquisa é de natureza exploratória e qualitativa. Seu objetivo é o de descrever e analisar os sites de duas empresas, focalizando os RNF e a usabilidade fornecida aos usuários. Para conduzir a análise, o estudo usou uma taxonomia (descrita mais adiante neste artigo), desenvolvida com base na literatura e na experiência dos autores, que descreve, enumera e classifica tais requisitos. Ambos os sites foram acessados e avaliados para cada requisito da taxonomia. $\mathrm{O}$ uso dos requisitos é descrito através de texto e reprodução de imagens dos sites.

Para a escolha dos sites, buscaram empresas que atuassem no mesmo ramo de negócios e fossem: uma brasileira, a "ingresso.com.br", e outra

Devido a esse papel crucial da informação, as interfaces dos sites das empresas, parte visível de um sistema, devem ser projetadas com o propósito de estabelecer uma interação produtiva entre o sistema e seus usuários (FERREIRA, 2004).

Para isso, é necessário garantir que os RNF de usabilidade sejam tratados durante a definição do produto (BIAS, 1994; CYSNEIROS, 2001). Os RNF, ao contrário dos funcionais, não expressam nenhuma função (transformação) a ser implementada em um sistema de informações; eles expressam condições de comportamento e restrições que devem prevalecer (SOMMERVILLE, 2004).

Quando organizações globalizadas negociam fora de suas esferas nacionais, elas se tornam uma ameaça para as companhias locais. Por outro lado, a Internet permite que pequenas empresas, através de seus sistemas Web, tirem partido de novas oportunidades de mercado, podendo formar alianças estratégicas e, até, operar de maneira global (O'BRIEN, 2001). Os sistemas de informação baseados na Web, além de desempenhar um importante papel no tratamento, processamento e distribuição da informação, estão se tornando essenciais para as organizações, por permitir novas modalidades de negócio e constituir um importante canal de marketing (FERREIRA, 2004_B).

O presente trabalho é uma extensão de trabalhos anteriores (FERREIRA, 2002, 2003, 2004) sobre RNF de usabilidade, que, em 2004, começaram a abordar a questão da usabilidade de sistemas de informação globalizados. Seu objetivo é o de comparar os sites de duas empresas multinacional, a "ticketmaster.com.br".

A Ingresso foi fundada em 1995 e foi a primeira organização estabelecida no País com o propósito de vender ingressos de cinema, shows e teatro na Internet. Tornou-se líder na venda de ingressos para cinema on-line. Em 2003, seu site ganhou o prêmio iBest, o mais importante prêmio da Internet brasileira (http_2).

A Ticketmaster.com é a empresa líder mundial de vendas de ingresso e possui um dos maiores sites de comércio eletrônico. Começou a atuar no Brasil em 2000, vendendo ingressos para shows, teatros, parques de diversão e alguns eventos especiais. Até o momento de realização da pesquisa, não comercializava ingressos de cinema (http_3).

Dada a sua atividade, é essencial para ambas as organizações que seus sites sejam fáceis de usar (COGBURN, 2003). A facilidade de uso pode ser determinante para conquistar os clientes e obter sua lealdade, contribuindo assim para o sucesso ou o fracasso do negócio.

\section{REQUISITOS NÃO FUNCIONAIS — RNF}

Os RNF, para qualquer tipo de sistema, estão relacionados a aspectos de software, hardware ou fatores externos, que determinem condições ou restrições ao comportamento do sistema pretendido (SOMMERVILLE, 1997, 2004) e (PRESSMAN, 2004). Entre estes requisitos podem-se citar: desempenho, segurança, portabilidade, confiabilidade. manutenibilidade, acessibilidade, usabilidade, etc. 
Assim como os demais sistemas de software, os sistemas de informação baseados na Web necessitam atender aos RNF, os quais devem ser especificados com clareza. Neste trabalho, foi dada atenção especial aos aspectos de usabilidade, pois os sistemas de informação baseados na Web apresentam ainda uma tecnologia de interface recente e com grandes desafios a serem vencidos.

\section{Usabilidade}

As organizações começaram a desenvolver sistemas de informação baseados na Web de modo a melhor se posicionarem em uma nova modalidade de negócios. Como a tecnologia usada para construir Web sites traz a possibilidade de lidar com imagens, sons e recursos visuais de edição de texto, tornouse evidente que a exibição da informação deve ser tratada com cuidado (FERREIRA, 2002).

A interface com o usuário, parte visível dos sistemas, através da qual a comunicação entre o homem e o sistema (site) é estabelecida, acabou se tornando uma parte essencial de um sistema. Um bom sistema deve garantir uma comunicação transparente, isto é, sua interface deve ser usada para se executar uma tarefa sem chamar atenção para si, de modo a permitir que os usuários não precisem focalizar sua energia na interface em si, mas apenas no trabalho que desejam executar (NORMAN, 1986, 1999; JOKELA, 2004; SEFFAH, 2004). Isso significa que a interface deve ser projetada com todo o cuidado. Para isso, é necessário garantir que os aspectos de cunho não-funcional sejam tratados adequadamente e no tempo apropriado, isto é durante a definição do produto (BIAS, 1994; CYSNEIROS, 2001).

Vários são os casos em que o pouco cuidado com aspectos não-funcionais levou a situações de desastre (BREITMAN, 1999; DAVIS, 1993; CYSNEIROS, 1999). O presente artigo se propõe a mostrar como é importante considerar esses aspectos quando se está projetando sites que demandam que seus clientes percebam, processem e usem a informação para encontrar produtos, estimar seu valor e adquiri-los.

Figura 1: Taxonomia proposta.

A usabilidade é a característica que determina se o manuseio de um produto é fácil e rapidamente aprendido, dificilmente esquecido, não provoca erros operacionais, oferece um alto grau de satisfação para seus usuários, e eficientemente resolve as tarefas para as quais ele foi projetado (FERREIRA, 2003; JOKELA, 2004; SEFFAH, 2004). É, portanto, essencial em tais sistemas.

\section{TAXONOMIA}

A Figura 1 apresenta a taxonomia proposta, desenvolvida com base em uma série de trabalhos já disponíveis na literatura (FOLEY, 1997; LAUREL, 1990; NIELSEN, 2000, 2002; PRESSMAN, 2004; SHNEIDERMAN, 1997; TOGNAZZINI, 1995) e na experiência prática dos autores sobre o tópico. A taxonomia é organizada em duas categorias principais: exibição da informação e entrada de dados.

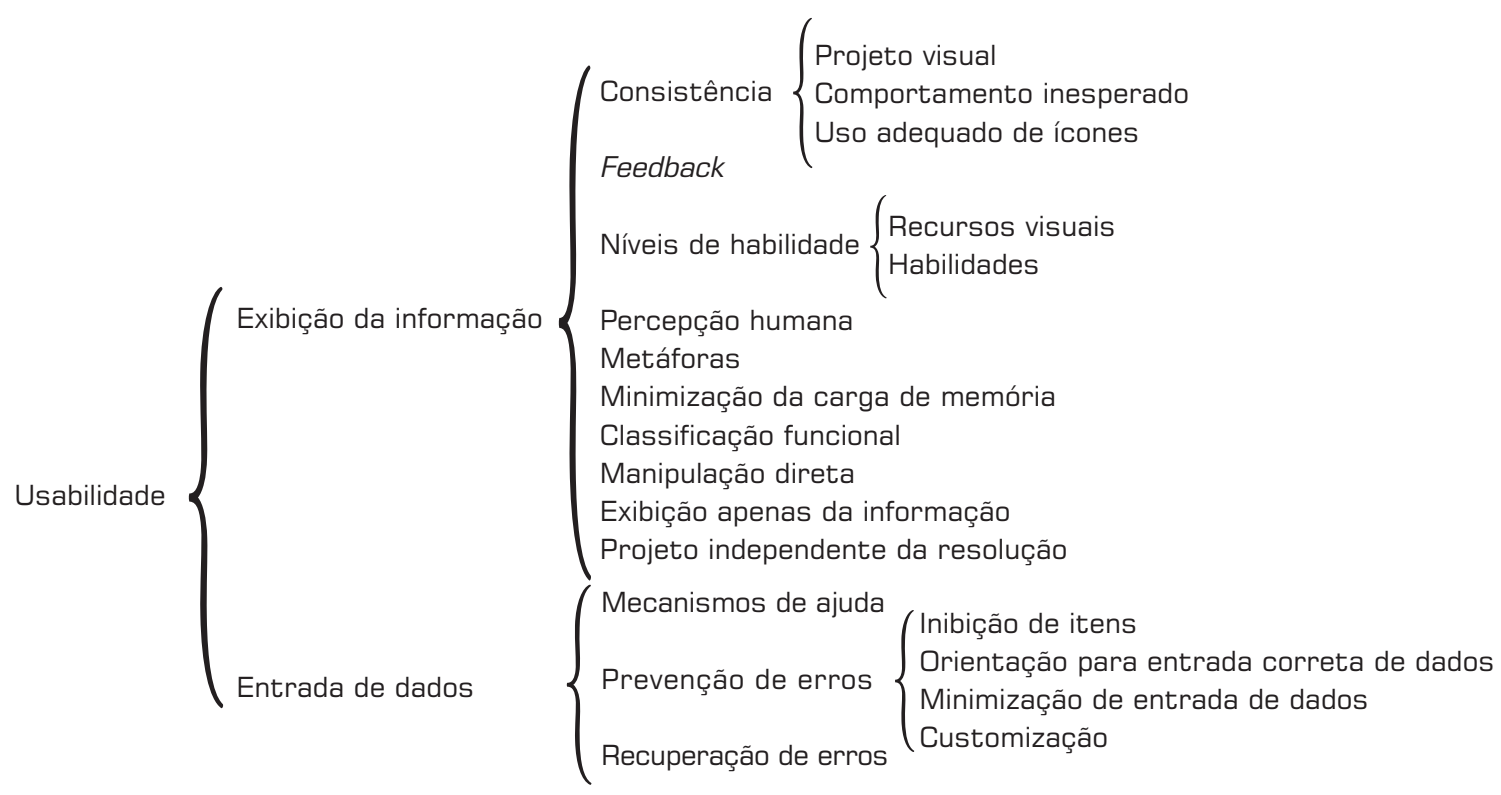




\section{Categoria Exibição da Informação}

\section{Consistência}

A consistência é uma das principais características para a usabilidade de uma interface (NIELSEN, 2000, 2002; PEARROW, 2000). Ela reduz a frustração provocada por comportamentos inesperados e logicamente incompreensíveis do sistema. Além disso, permite que uma pessoa generalize o conhecimento de um aspecto do sistema para os outros (FOLEY, 1997). Para ser consistente, é necessário que os menus, comandos de entrada, exibições de informação, e todas as funções de uma interface possuam a mesma apresentação visual e o mesmo comportamento.

A fim de exemplificar os principais aspectos envolvidos no requisito de consistência, foram selecionadas duas interfaces semelhantes de cada site: a página principal e a página da cidade do Rio de Janeiro. A Figura 1.A mostra a home page do site "ingresso.com.br" e a Figura 1.B mostra a página do Rio de Janeiro dessa empresa; a Figura 1.C mostra a home-page da "ticketmaster.com.br" e a Figura 1.D sua página do Rio de Janeiro.

As interfaces do site "ingresso.com.br" de forma geral são mais consistentes do que as do site "ticketmaster.com.br". Na realidade, ambos os sites apresentam uma série de inconsistências. A seguir são descritos alguns exemplos.

\section{Projeto Visual}

Naturalmente, o usuário, ao navegar por um site, espera que suas páginas tenham sempre a mesma aparência, não importa em que parte do site ele se encontre. Todas as páginas do "ingresso.com.br" (Figuras 2.Ae 2.B) possuem os mesmos layouts e exibem ao usuário as mesmas características.

Já as do "ticketmaster.com.br" possuem aparência distinta entre si. A Figura 2.C mostra um menu lateral (elipses cinzas) com opções de eventos que uma pessoa pode adquirir, menu esse não exibido na Figura 2.D. Se um usuário resolver entrar na página do Rio de Janeiro e saber que tipos de eventos ele pode comprar, ele antes precisará escolher um item extra, que é a opção "Casa de Espetáculo" (retângulo azul) do menu horizontal. Na realidade, ao selecionar uma página de uma cidade específica, como da Figura 2.D, a única opção exibida na parte central da página é chamada "Eventos", o que pode levar o usuário a acreditar que não pode comprar ingressos para teatro, jogos, etc. Para comprar esses ingressos ele tem que adivinhar que precisa clicar na opção "Casa de Espetáculo" (retângulo azul) do menu horizontal.

Figura 2: Mesmas páginas dos sites ingresso.com.br e ticketmaster.com.br.br.

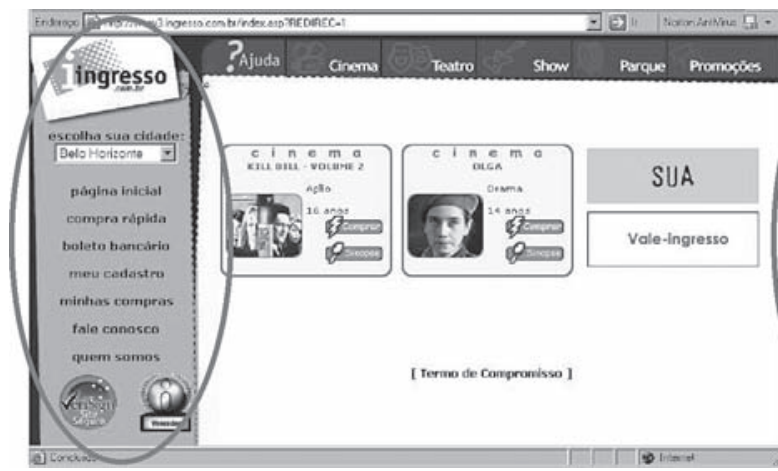

(A)

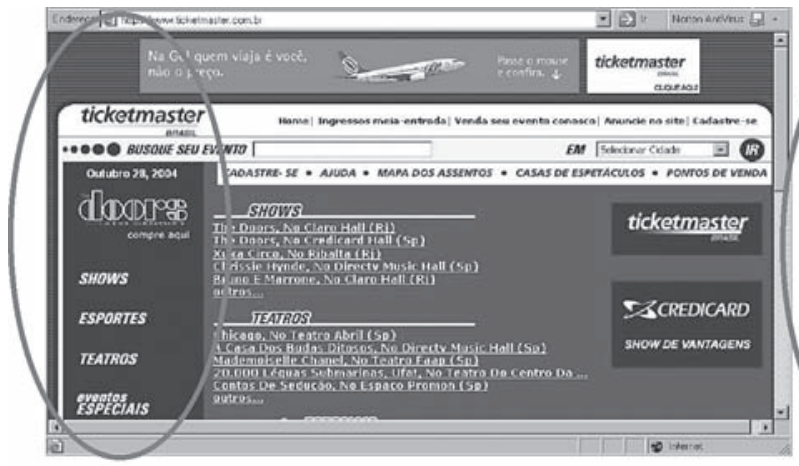

(C)

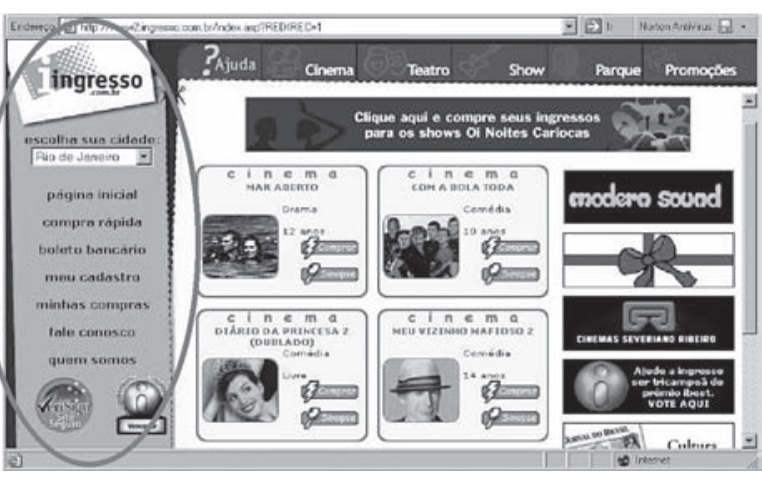

(B)

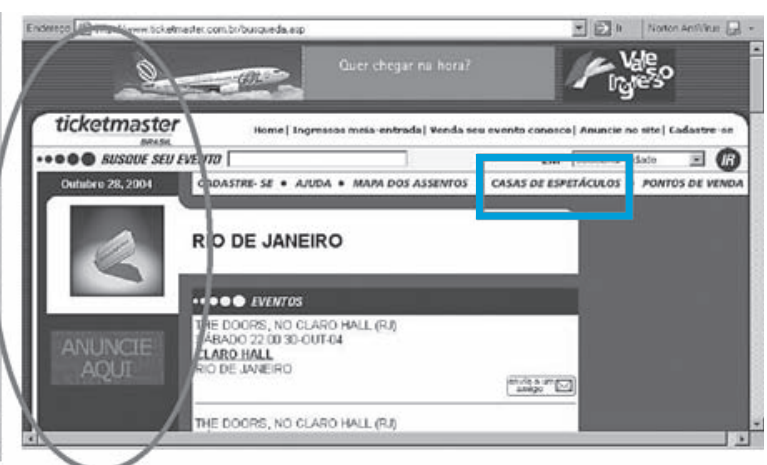

(D) 


\section{Comportamentos Inesperados}

Um grave problema de usabilidade é a ocorrência de comportamentos inesperados causados por design inadequado. No "ingresso.com.br", quando um usuário seleciona a opção "Ajuda", localizada no menu horizontal superior, é aberta uma nova página chamada "Perguntas mais freqüentes" (Figura 3.A). Isso pode confundir o usuário, que provavelmente está imaginado que será exibida uma página denominada "Ajuda". Esse problema não ocorre no "ticketmaster.com. br", que, na mesma situação, abre uma página apropriadamente chamada de "Ajuda" (Figura 3.B).Uso apropriado de ícones: "uso de diferentes ícones para uma mesma ação" ou "uso de um mesmo ícone para funções diferentes"

Outro problema freqüente é o uso de diferentes ícones para a mesma ação ou o uso de um mesmo ícone para funções diferentes. Um ícone é um pictograma que indica visualmente a existência de uma aplicação, ou representa uma função, um objeto, uma ação, uma propriedade ou qualquer outro conceito (FOLEY, 1997).

$\mathrm{O}$ "ingresso.com.br" usa ícones diferentes para a mesma função e usa diferentes ícones para a mesma função. As Figuras 4.A e 4.B mostram o uso de dois ícones distintos para a ação de “comprar". As Figuras 4.B e 4.C mostram dois ícones muito semelhantes (eles só diferem um do outro pelo texto exibido acima deles) para duas ações diferentes: "comprar" e "continuar". Apesar do texto diferente, teria sido melhor usar ícones distintos, evitando assim que o usuário se confunda.

Como a interface do "ticketmaster.com.br" não é icônica, não apresentou esse problema. Mas deve ser realçado que o não uso de ícones não constitui uma boa técnica de usabilidade (FERREIRA, 2003).

\section{Feedback}

Em qualquer forma de comunicação, ofeedbacké importante. Quando duas pessoas conversam, elas estão constantemente dando um feedback uma à outra, através de gestos, expressões e outros. Para uma boa interação de uma pessoa com o computador, o mesmo deve acontecer, porém nesse caso, o feedback deve ser planejado e programado (FOLEY, 1997). As interfaces do "ingresso.com.br" apresentam mais dessas facilidades.

Nos dois sites, sobretudo no "ticketmaster.com.br", faltam feedbacks relacionados aos links. Nenhum dos dois altera a aparência dos links visitados (por exemplo, trocando de cor). O Ingresso realça o link que o usuário está prestes a escolher (quando o mouse se encontra sobre o link) (Figura 5), mas o "ticketmaster.com.br" não.

Figura 3: As páginas "Ajuda" de ambos os sites.
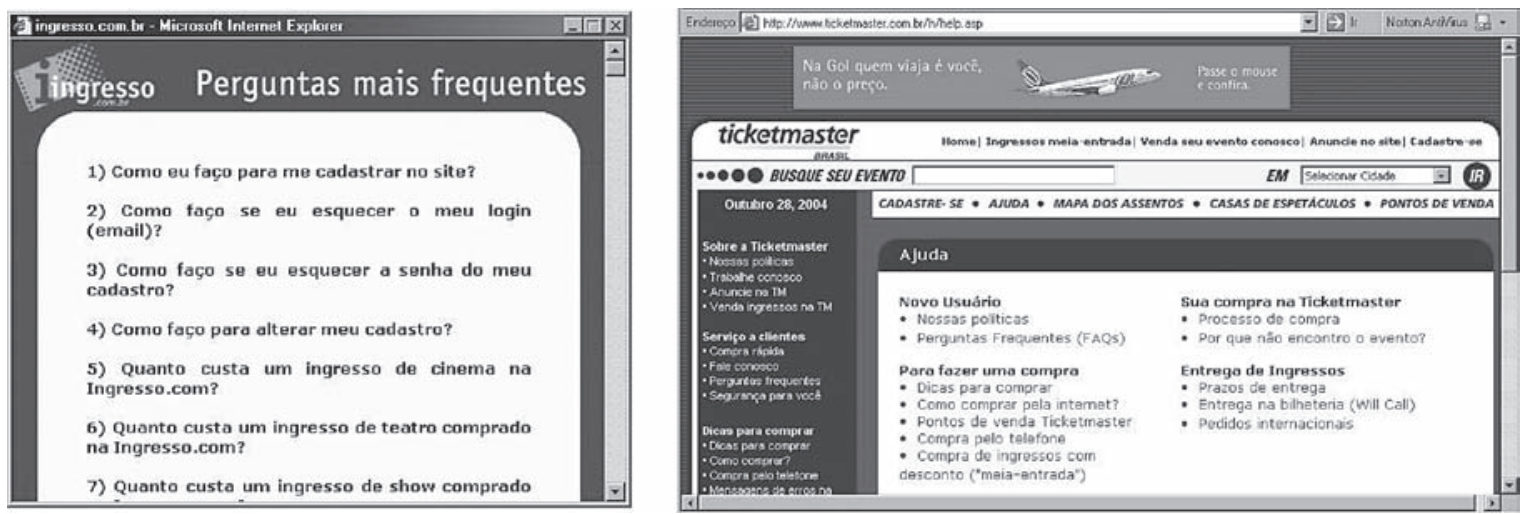

Figura 4: 0 uso de ícones semelhantes ações distintas no ingresso.com.br

COHPBAR

(A)

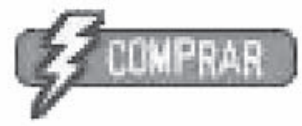

(B)
ODNTIRUAR

(C) 
Outro exemplo de um bom feedback presente somente no ingresso é a mensagem de alerta exibida quando o usuário tenta comprar um ingresso para um evento não exibido na cidade selecionada (Figura 6).

\section{Níveis de Habilidade e Comportamento Humano}

Uma interface deve ser projetada de modo a poder ser usada tanto por usuários experientes como por novatos; para isso ela deve ter algumas peculiaridades.

\section{Uso de Recursos Visuais}

Recursos visuais, como fotografias e ícones, são excelentes ferramentas para principiantes, pois os ajudam a visualizar melhor suas ações.

Ícones bem projetados podem ser reconhecidos mais rapidamente que palavras; se bem escolhidos, tornamse independentes de idioma, possibilitando o uso da interface em diversos países sem a necessidade de tradução. Ícones bem projetados devem ter as seguintes características:

1. Fácil Reconhecimento: rapidez com que seu significado é captado.

2. Fácil Recordação: rapidez com que seu significado é relembrado uma vez esquecido.

3. Fácil Discriminação: facilidade com que um ícone pode ser distinguido de outro.

O "ticketmaster.com.br" não possui interfaces tipicamente icônicas; o site usa poucos recursos visuais, apenas alguns ícones (Figura 7). Já o site da "ingresso.com.br” usa os recursos visuais de forma adequada: ele mostra imagens dos eventos como filmes, shows (Figura 8.A) e usa os ícones de modo útil, adaptados às diversas seções (Figura 8.B).

O único ícone de fácil reconhecimento usado no

Figura 5: Ingresso.com.br realça os links prestes a serem visitados.

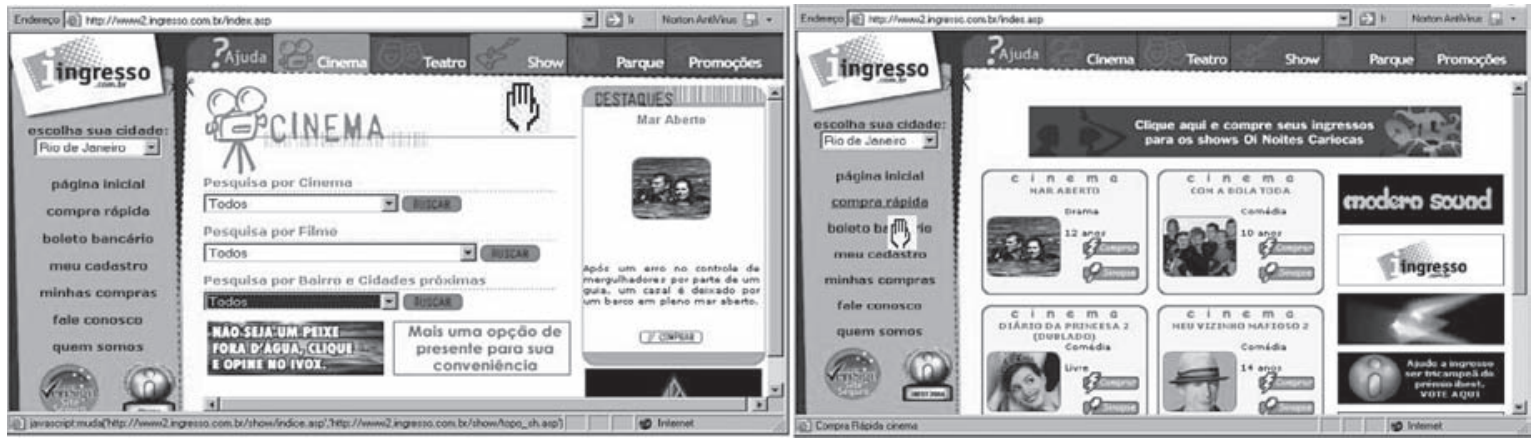

Figura 6: Mensagem do Ingresso.com.br indicando a não disponibilidade de alguns ingressos.

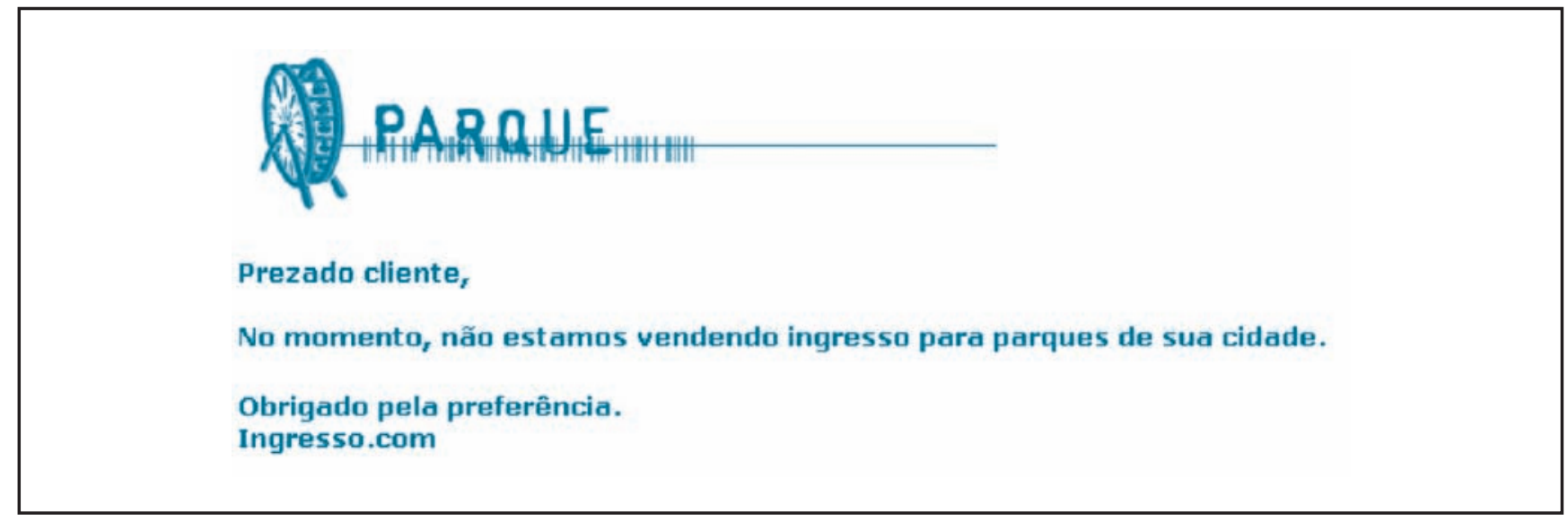


"ticketmaster.com.br" é o relacionado à ação "Compra pelo telefone" (primeiro ícone da Figura 7); os outros três ícones ("Casas de Espetáculos Ticketmaster", "Ticketmaster no Mundo" e "Trabalhe Conosco") não são facilmente reconhecidos. Como o "ticketmaster.com.br" usa poucos ícones, eles naturalmente são fáceis de serem lembrados e discriminados.

Já os ícones do "ingresso.com.br" são melhor planejados (Figura 8.B). Alguns exibidos no presente artigo, como "cinema"e "teatro" são muito fáceis de serem reconhecidos, lembrados e discriminados. Os demais ícones analisados são tão semelhantes entre si (com exceção do ícone "cadastre-se aqui"), que se tornam de difícil recordação e discriminação.

\section{Uso de outras facilidades}

Facilidades como menus, formulários e prompts são de grande ajuda aos novatos e estão presentes ao longo de todos os dois sites. Como essas facilidades muitas vezes são consideradas lentas pelos mais experientes, interfaces bem projetadas devem permitir também o uso de aceleradores, isto é, teclas de função e comandos usados via teclado, que tornam a interação mais rápida (FOLEY, 1997). Ambos os sites permitem que o usuário navegue usando o teclado.

\section{Percepção Humana}

Variações de habilidades físicas, comportamento e personalidade influem no êxito de um sistema. Cada usuário possui um estilo cognitivo, que determina como ele percebe a informação. Para se criar uma interface que de fato possa ser usada por diferentes pessoas, deve-se poder apresentar seu conteúdo de diversas formas, de modo a acomodar as diferentes percepções (PRESSMAN, 2004).

\title{
- m uma boa interface, o usuário só precisa concentrar sua energia na tarefa que ele deseja realizar.
}

Figura 7: Poucos ícones usados no site da ticketmaster.com.br

\begin{abstract}
Apesar da forte tendência de se utilizar elementos gráficos no projeto de Web sites, a leitura ainda constitui uma atividade essencial em muitos sistemas. O tamanho do texto, o tipo de fonte, o comprimento de uma linha, as letras maiúsculas/minúsculas, a localização e cor são fatores que afetam a facilidade com a qual a informação é percebida, isto é, sua usabilidade.

No site "ingresso.com.br" não foi observado nenhum problema que dificulte a percepção dos elementos.
\end{abstract}

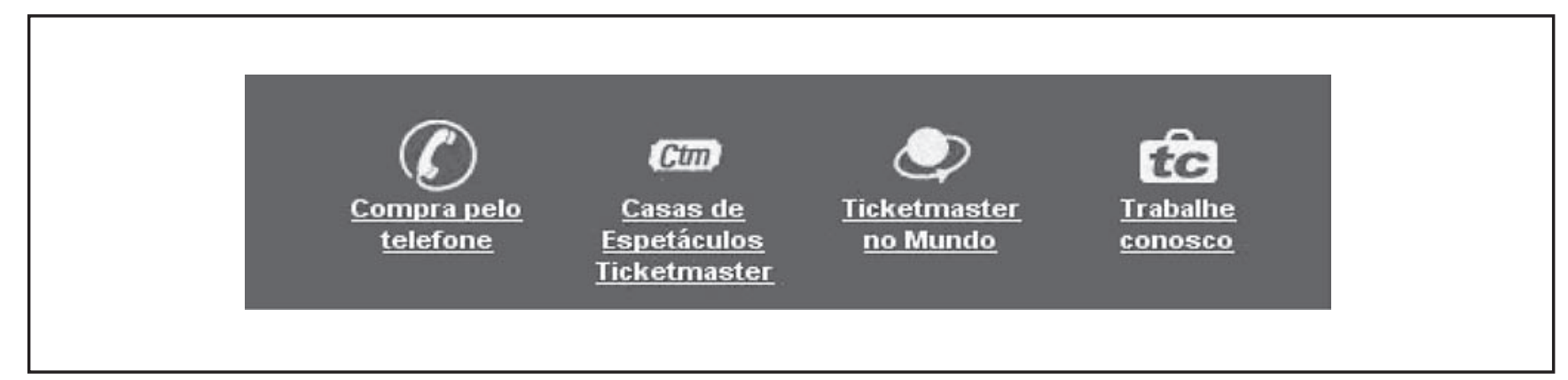

Figura 8: Imagens relacionadas a cada seção do site ingresso.com.br

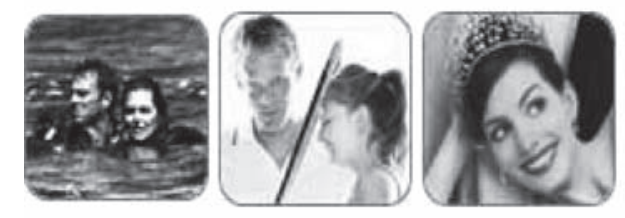

(A)

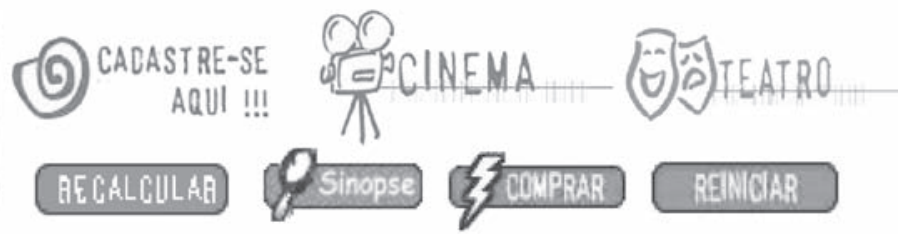

(B) 
O site "ticketmaster.br" apresenta uma característica que compromete muito a percepção de seus elementos. A Figura 9.A mostra um banner (elipse cinza) presente em todas as páginas do site que gera um problema: quando o mouse passa por cima do banner, ele se torna uma janela que aparece sobre toda a página corrente (Figura 9.B), dificultando a percepção da informação de fato desejada. $\mathrm{O}$ usuário deve clicar em qualquer parte da página corrente, de modo a fazer com que tal janela desapareça; usuários novatos podem não descobrir isso.
Com base nessa propriedade, as cores podem ser usadas para ajudar os usuários a navegar pelo site.

No "ticketmaster.com.br", o elemento cor não parece ter sido utilizado com o propósito de otimizar a comunicação. Basicamente todas as páginas possuem um fundo azul com fontes brancas. Cores distintas poderiam ter sido usadas para ajudar os usuários a identificar diferentes itens (cada página relacionada às seções "shows", "esportes", "teatros" etc. poderia ter sido projetada com cores diferentes). Aparentemente, o site foi projetado sem que fosse considerado o fato de que pessoas associam as cores com situações da vida.

Já no site "ingresso.com.br", cores diferentes foram utilizadas para indicar cada seção (Figura 10.A: "Cinema": verde; Figura 10.B: "Teatro": laranja; Figura 10.C: "Show": vermelha e Figura 10.D: "Parque": roxa).

\section{Uso Adequado da Combinação de Cores}

A cor, elemento fundamental em qualquer processo de comunicação, interfere nos sentidos, emoções e intelecto de uma pessoa (MARCUS, 1987). Por isso, a combinação de cores deve ser cuidadosamente escolhida (MARCUS, 1987, 1998; JACKSON, 1994; FERREIRA, 2002).

$\mathrm{O}$ uso apropriado de cores pode resultar em uma rápida e correta assimilação da informação. Seu impacto na eficácia da interface depende da relevância de seu uso para a execução de uma tarefa e da situação e ambiente onde a tarefa ocorre (SMITH, 1987).

Além disso, o projetista deve estar atento ao fato de que as pessoas associam cores com diversas situações em suas vidas. Essas associações dependem de muitos aspectos: localização geográfica, cultura, idade (JACKSON, 1994).

\section{Metáforas}

O projetista de interface deve aproveitar o conhecimento que o usuário possui a respeito do mundo que o cerca; o uso de metáforas que envolvam idéias já familiares torna a interação mais intuitiva e menos hostil (APPLE, 1992).

O “ticketmaster.com.br" é pobre no uso de metáforas e, quando as utiliza, o faz de forma confusa. A Figura 11 mostra alguns exemplos. A Figura 11.A representa a possibilidade de se comprar ingressos em todas as partes do mundo. Teria sido melhor se um ícone com o desenho de um globo tivesse sido adotado. A Figura 11.B indica a possibilidade de se trabalhar na companhia, mas seu significado é de difícil compreensão.

O "ingresso.com.br" também é pobre no uso de metáforas, mas quando as utiliza, o faz de forma mais apropriada. A Figura 12 mostra as metáforas adotadas

Figura 9: Características que dificultam a percepção no site ticketmaster.com.br.

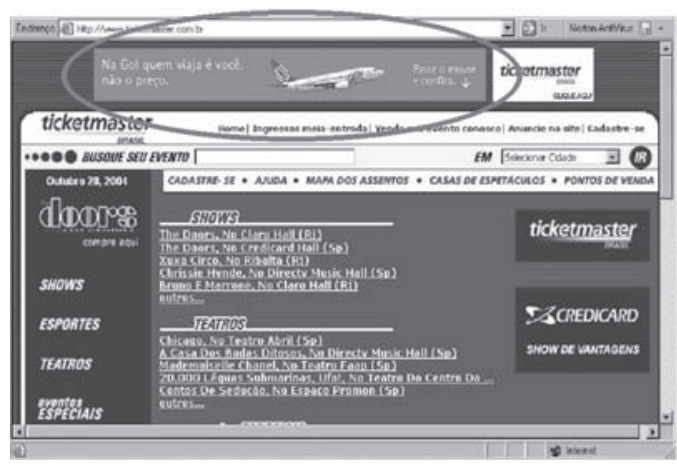

(A)

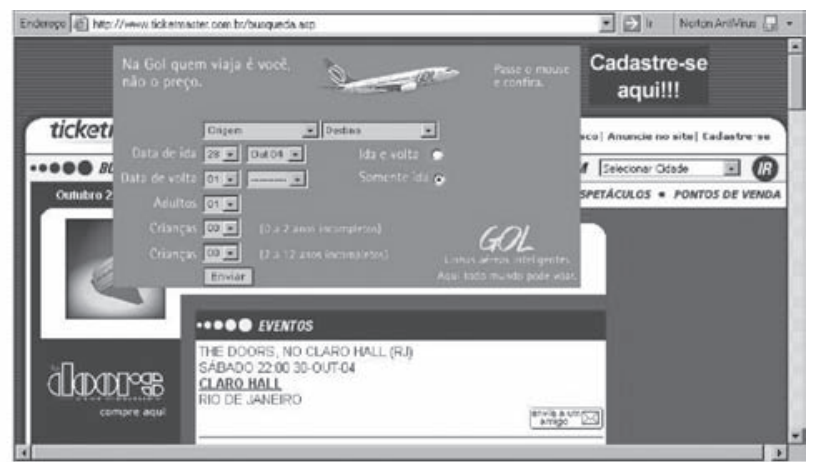

(B) 
para cinemas (12.A), teatro (12.B) e presentes (12.C). São metáforas simples porém poderosas. As pessoas rapidamente reconhecem seus significados.

\section{Minimização de Carga de Memória}

Uma boa interface deve exigir pouco esforço dos usuários para memorizar os aspectos do site (FOLEY, 1997); a interface do "ticketmaster.com.br" algumas vezes exige uma memorização desnecessária: poucos comandos mnemônicos são usados e os ícones não são bem projetados, o que torna a memorização não trivial. Já a interface do "ingresso. com.br" é mais amigável nesse aspecto.

\section{Classificação Funcional dos Comandos}

As barras de menu fornecem uma lista de opções para o usuário; elas apresentam-se como uma boa maneira de acessar funções não constantemente solicitadas. Seu conteúdo depende do site, mas, geralmente, as diversas páginas de um site possuem barras semelhantes, com seus itens dispostos um ao lado do outro, no caso de menus horizontais, ou um

Figura 10: Uso de cores distintas para seções diferentes no site Ingresso.com.br

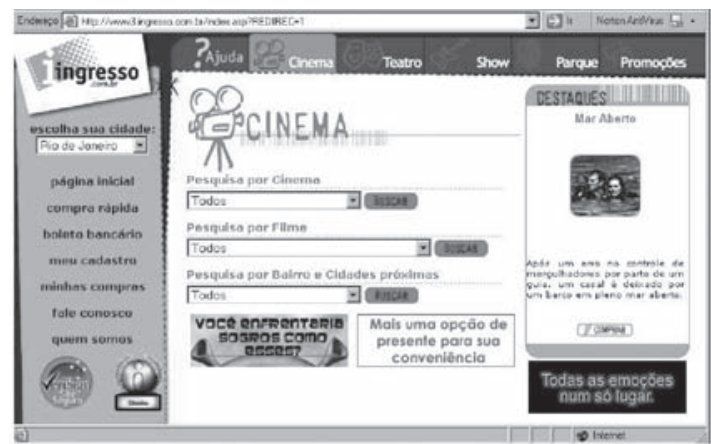

(A)

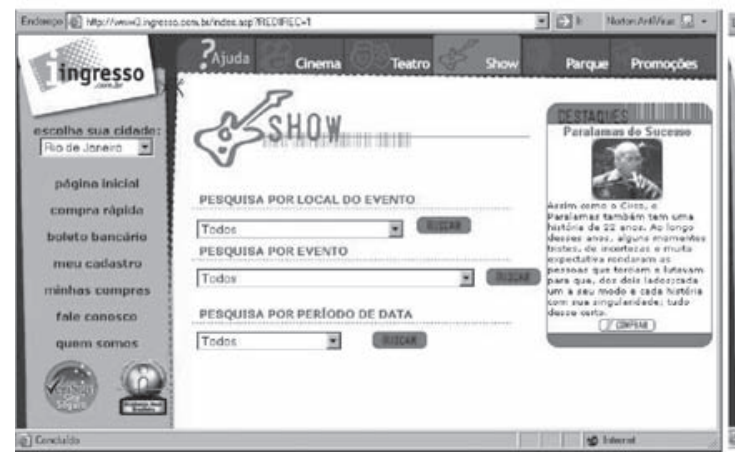

(C)

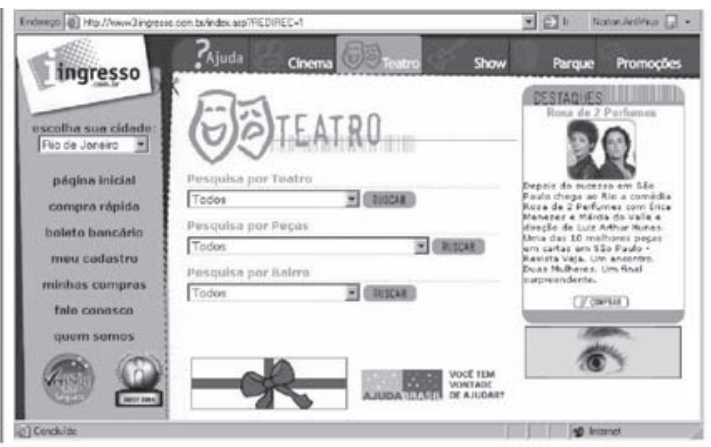

(B)

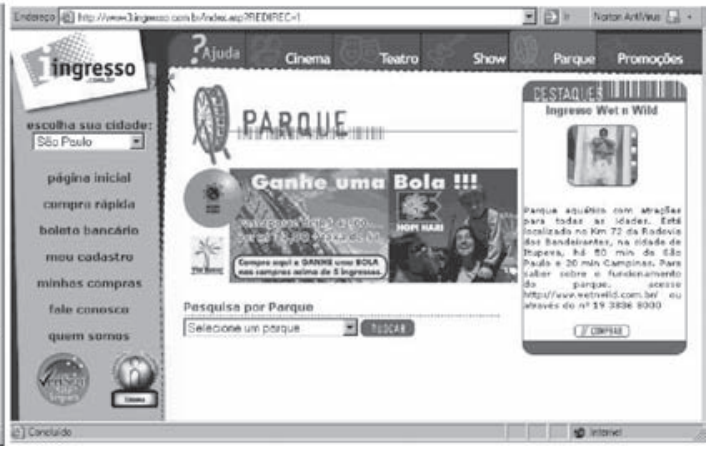

(D)

Figura 11: Algumas metáforas usadas no site tickemaster.com.br

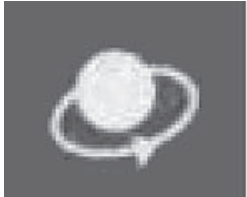

(A)

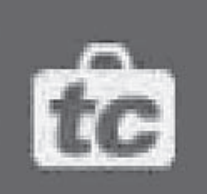

[B] 
abaixo do outro, no caso de menus verticais.

O termo "menu" é uma metáfora com os cardápios de restaurantes e segue a idéia destes. Normalmente, em um cardápio, as opções são agrupadas abaixo de um título (aves, frutos do mar, massas, etc.). Da mesma forma, no menu de uma interface, as opções são agrupadas segundo algum critério estabelecido pelo projetista, geralmente o de sua funcionalidade.

Ao lidar com uma série de itens, as pessoas se sentem mais confortáveis quando o número de itens é de, no máximo, sete mais ou menos dois (Lei de Miller) (FERREIRA, 2002). Isto é, um menu não deveria comportar mais que sete mais ou menos dois itens. O menu de ambos os sites obedece à lei de Miller.

\section{- importante que a informação flua adequadamente através de toda organização e entre a organização e seus clientes.}

confundindo o usuário. Os menus do site "ingresso.com.br" trazem itens adequadamente classificados.

\section{Manipulação direta}

A manipulação direta dá às pessoas a sensação de que estão controlando os objetos representados no computador; o objeto manipulado deve permanecer visível enquanto estiver sendo realizada uma operação sobre ele e o efeito dessa operação deve ser imediatamente notado (APPLE, 1992). Por exemplo, quando o mouse passa sobre um objeto, esse deve ser realçado. Isso acontece no site "ingresso.com.br", mas não no "ticketmaster.com.br".

\section{Exibição apenas da informação relevante ao contexto}

Para ser assimilada com mais facilidade, apenas a informação relevante no contexto corrente deve ser mostrada; o usuário não deve ter que ficar procurando, no meio de muitos dados, aquilo de que precisa para executar sua tarefa. Para isso, devem ser usadas, sempre que possível, janelas

Mas, no menu exibido no meio da página principal do site "ticketmaster.com.br" (Figura 1. C), embora as opções sejam mostradas de acordo com a Lei de Miller, os itens listados não são classificados de forma apropriada.; opções de diferentes tipos de diversões e diferentes cidades são encontradas na mesma parte do menu. Por exemplo, abaixo do item "Teatro", opções de muitas cidades podem ser achadas. Isso poderia ter sido adequadamente projetado se o projetista do site tivesse agrupado as opções de acordo com algum critério funcional, como localização geográfica e tipo de diversão.

Seria melhor se os nomes das cidades fossem exibidos e, uma vez escolhida a cidade, fossem mostrados submenus por meio de menus pull-down ou menus hierárquicos. Uma das vantagens de menus pull-down é que eles só são chamados quando necessários, economizando espaço de tela e evitando a exibição desnecessária de opções que podem acabar distintas para mostrar informações de diferentes tipos e pelo menos uma parte de cada janela deve poder ser vista (PRESSMAN, 2004).

Os dois sites analisados fazem isso (figuras 13.A e 13.B), mas eles poderiam explorar melhor esse recurso.

As páginas do "ticketmaster.com.br" são repletas de informações que tornam o processo de localizar algum elemento difícil, podendo desviar a atenção do usuário (como visto na Figura 1.C).

\section{Projeto independente da resolução do monitor}

Um outro problema que interfere na usabilidade dos sites, é a questão da resolução. Em interfaces tradicionais, o projetista sabe para que ambiente ele está projetando; ele tem total controle sobre cada pixel da tela que aparece para o usuário e pode ter certeza que cada elemento projetado será visualizado sempre da mesma forma nas telas, indepen-

Figura 12: Algumas metáforas usadas no site do Ingresso.com.br
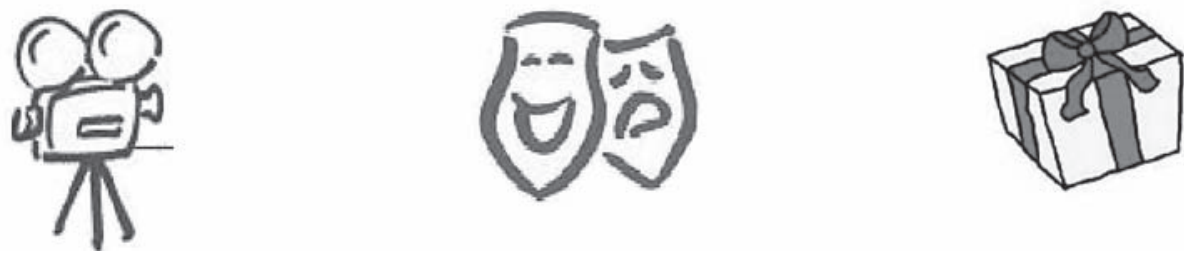
dentemente da resolução de seu monitor. O projetista pode escolher adequadamente os aspectos visuais da interface, como tipo de fonte, tamanho, entre outros.

Como na Web o projetista não consegue controlar como a aparência da interface será exibida, uma vez que o usuário pode acessar a Internet de diversas maneiras, o design para Web deve ser adequadamente planejado. Um dos princípios básicos é não projetar os elementos da interface com uma largura de tamanho fixo, determinada por um número de pixels; deve-se definir a aparência dos componentes através de percentagens do espaço disponível (NIELSEN, 2000, 2002). Isso realmente deve ser levado em conta, uma vez que muitas pessoas e organizações ainda possuem monitores de baixa resolução. Os dois sites estudados, quando exibidos em um monitor de baixa resolução, apresentaram problemas: importantes elementos dos sites desapareceram.

\section{Categoria Entrada de Dados}

Muito tempo de trabalho do usuário é gasto com a escolha de comandos, digitação de dados e outros inputs. Uma boa interface deve otimizar ao máximo o tempo que o usuário gasta com essas tarefas. As diretrizes apresentadas a seguir tornam a interface mais poderosa no que diz respeito à entrada de dados (PRESSMAN, 2004).

\section{Mecanismos de Ajuda}

Deve ser fornecida informação de ajuda para toda ação de entrada (FOLEY, 1997). Apesar de existir uma página de ajuda (Figura 14), onde o usuário pode achar detalhes sobre o site, nenhum dos sites oferece "dicas" quando o usuário passa com o mouse por cima dos elementos da tela. Esses recursos deveriam ter sido implementados; eles permitem que o usuário descubra a utilidade de muitos itens sem necessidade de recorrer ao manual.

O site "ingresso.com.br" é mais amigável quando se trata de mecanismos de ajuda. Ao longo de quase todas as interações, os usuários podem contar com muitos recursos, como o mostrado na Figura 14.

Figura 14: Mecanismo de ajuda presente no site "ingresso.com.br".

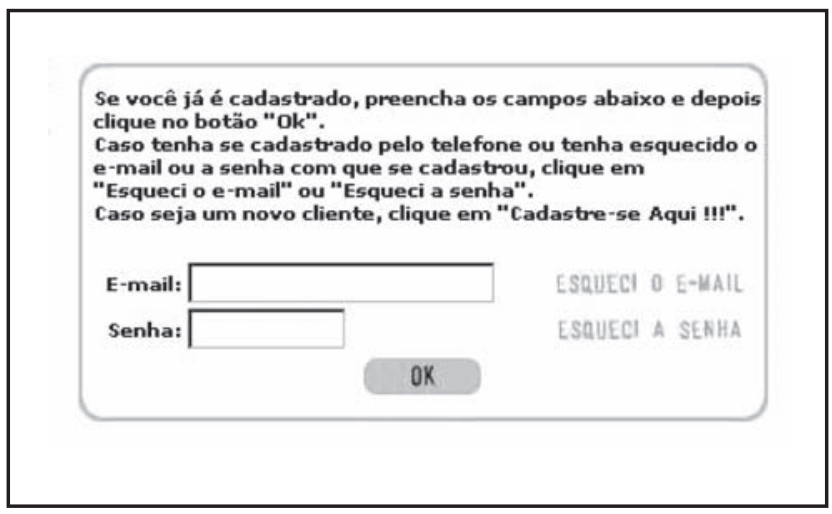

Figura 13: Os sites algumas vezes apresentam diferentes informações em diferentes janelas.

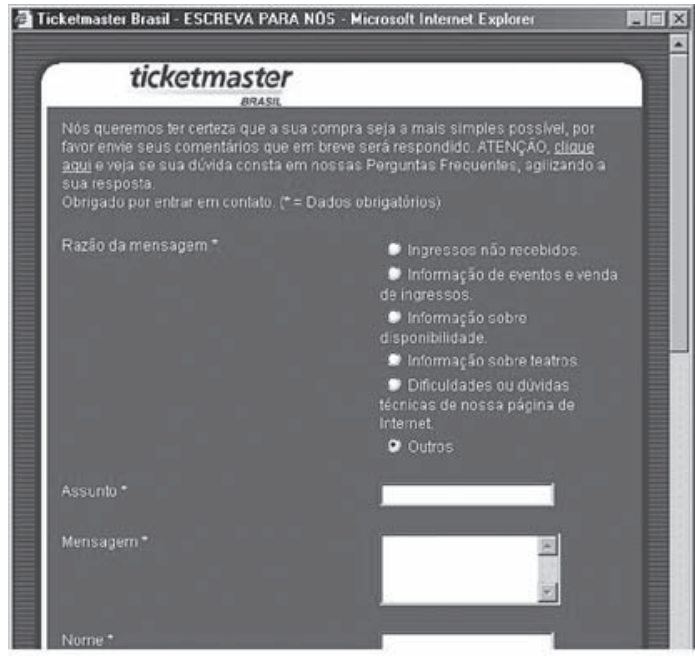

(A)

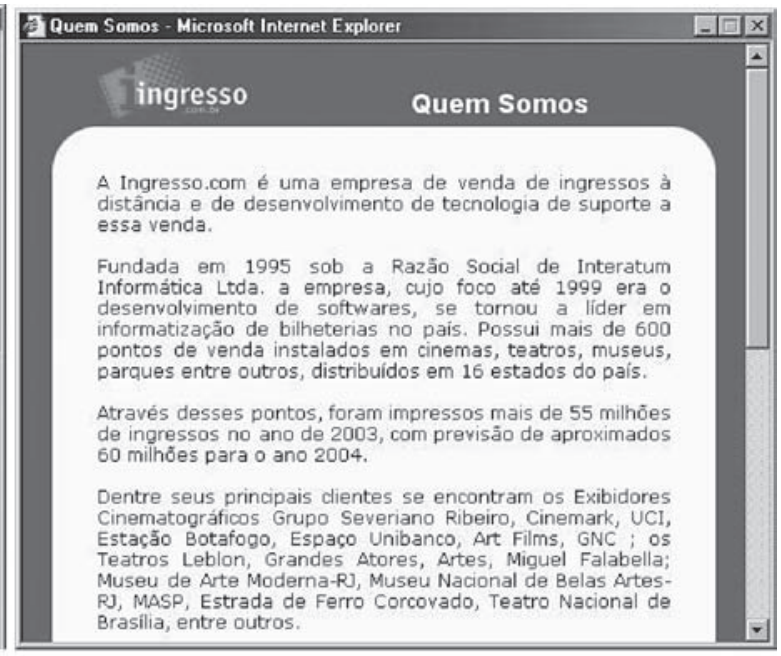

(B) 


\section{Prevenção de Erros}

Um dos objetivos de uma boa interface é evitar que seus usuários cometam erros. Uma interface bem projetada deve prover mecanismos de prevenção de erro de modo que o usuário não escolha uma opção inválida para só receber uma mensagem de erro (FOLEY, 1997). Ambos os sites apresentam alguns desses mecanismos:

\section{Inibição de itens não válidos}

Itens não válidos em um certo contexto não podem ser selecionados no estado corrente do sistema. Esses itens devem ser inibidos ou desabilitados através da mudança da aparência do item (por exemplo, troca de cor). Nenhum dos dois sites desabilita itens não válidos nem alerta para isso o usuário através de uma mudança na aparência do item.

Como já foi visto, ambos os sites permitem que o usuário escolha opções não válidas. Quando isso ocorre, o site "ingresso.com.br", apesar de deixar o usuário selecionar a opção, exibe uma mensagem indicando que a opção não está disponível (Figura 5). Já o site "ticketmaster.com.br" deixa o usuário escolher e depois apresenta um evento similar porém em outra cidade. Se o usuário não for atento, pode acabar comprando um ingresso para outra cidade sem nem perceber. A solução para ambos os sites seria inibir as opções dos eventos não disponíveis.

\section{Orientação para entrada correta de dados}

$\mathrm{O}$ usuário deve ser informado sobre a forma de preencher qualquer campo. Ambos os sites guiam o usuário nessa tarefa, como pode ser visto na Figura 15. Mas o site "ingresso.com. br" é melhor (Figura 15.A); a obrigação de preencher deter- minados campos é indicada através de um texto com uma cor diferente (vermelha), enquanto o "ticketmaster.com.br" usa a mesma cor do resto do site (preta) (Figura 15.B).

\section{Minimizar a quantidade de dados a ser entrada}

Uma boa interface minimiza o número de ações necessárias para a entrada de dados, reduzindo a tarefa do usuário de digitar. Ambos os sites oferecem tal facilidade, como, por exemplo, quando o usuário deseja se registrar, ao informar seu CEP, automaticamente o site preenche o nome da rua e o usuário não precisa entrar com esse dado. A Figura 16 mostra muitos recursos presentes nos dois sites que facilitam essa tarefa.

\section{Customização}

Uma boa interface deve permitir que o usuário "customize" seus comandos e mensagens. Nenhum dos dois sites permite customizações, nem mesmo uma simples alteração no tamanho da fonte do texto.

\section{Tratamento de Erros}

Todas as pessoas cometem erros, logo uma boa interface tem que fornecer recursos que permitam a correção desses erros o mais rápido possível (undo, cancel, correct ...); isso torna as pessoas mais produtivas e elas se sentem encorajadas a explorar o sistema, o que é uma maneira bem eficiente de se aprender as características do programa (FOLEY, 1997). Basicamente, existem dois tipos de erros: o funcional e o sintático.

1. Erros sintáticos: ocorrem quando uma seqüência de comandos (ou um único comando) é fornecida com pa-

Figura 15: Instruções para preenchimento de campos nos dois sites.

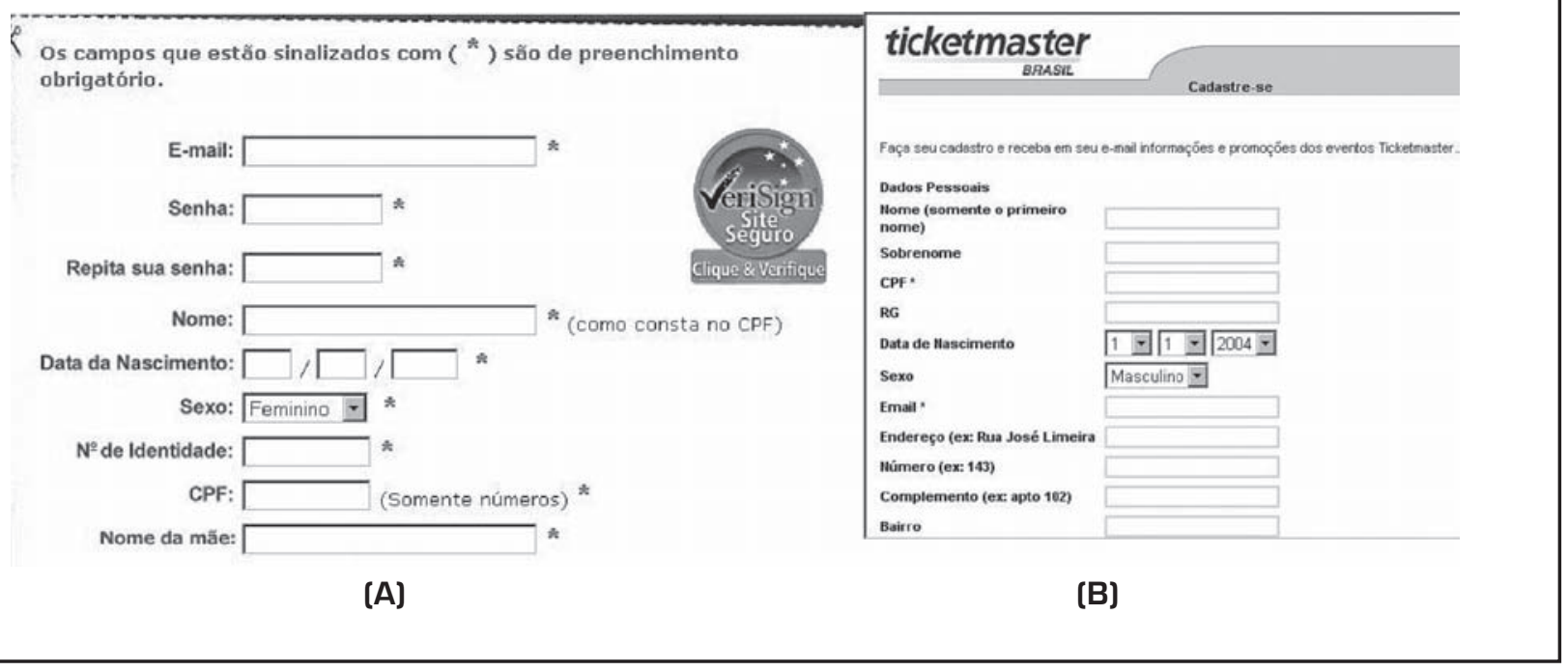


râmetros ou nomes errados; nesse caso, deve existir uma mensagem informativa e clara.

O "ticketmaster.com.br" foi melhor projetado para corrigir erros. A Figura 17.A mostra a mensagem exibida logo depois que o usuário digita seu CPF de forma errada em um formulário. $\mathrm{O}$ mesmo recurso existe no site "ingresso.com. br" mas, nesse caso, o site permite que a pessoa termine de preencher todo o formulário e só depois do seu envio ela recebe um aviso de erro (Figura 17.B). O usuário, nesse caso, precisa voltar para a página anterior e corrigir o CPF.

2. Erros funcionais: são os mais graves; ocorrem quando um comando é acionado por engano gerando resultados antecipados ou inesperados. Os sites estudados apresentam recursos de recuperação de erro funcional, como por exemplo a opção "cancelar" que aparece ao longo de todas as páginas dos dois sites, que permite ao usuário cancelar uma ação.

\section{Considerações sobre a Taxonomia Apresentada}

A taxonomia apresentada evidenciou uma série de pontos que devem ser considerados sobre a importância dos RNF de usabilidade na qualidade geral de um sistema. Ela pode ser utilizada para analisar iniciativas de comércio eletrônico, e a análise efetuada nos dois sites revelou vários aspectos que podem ser melhorados nesses sistemas específicos de

Figura 16: Opções de "contate-nos" nos dois sites.

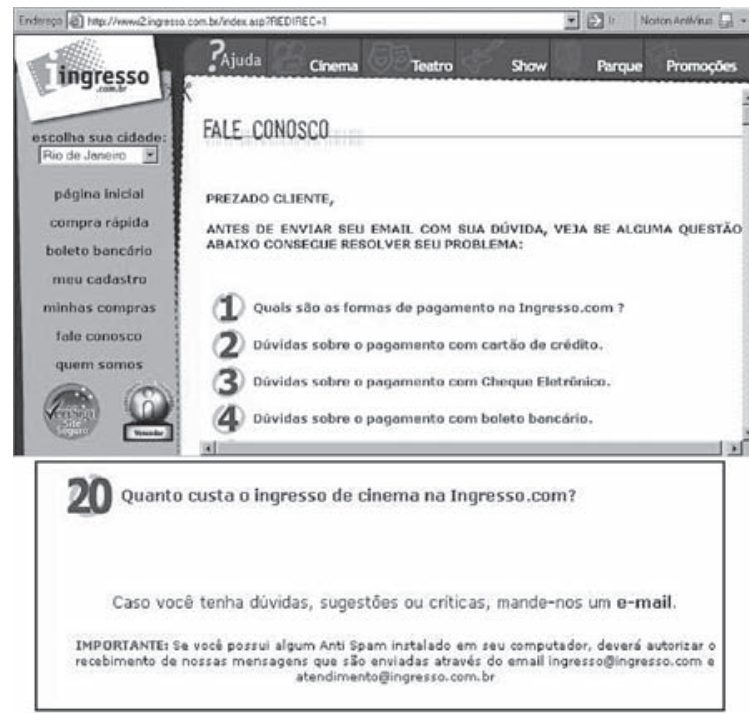

(A)

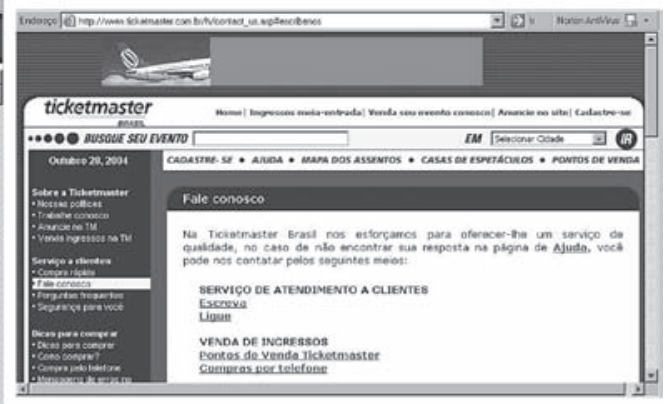

(B)

Figura 17: Mensagens apresentadas nos dois sites quando um erro sintático ocorre.

Dados Pessoais
Nome (somente o primeiro
nome)
Sobrenome
CPF
RG

Dados Pessoais nome)

Sobrenome

RG

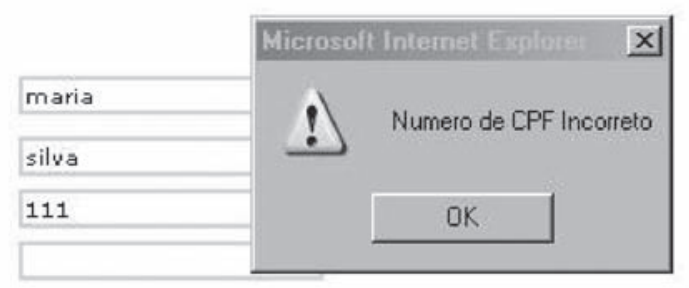

(A)

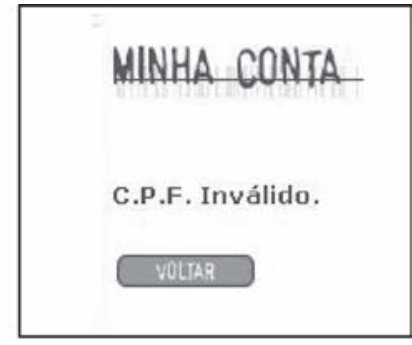

(B) 
comércio eletrônico. Com os exemplos reais analisados, procurou-se mostrar que a atenção dada à definição de requisitos não funcionais pode ter forte impacto na qualidade do sistema de informação, principalmente naqueles que apresentam software de interação direta com clientes da organização. As tabelas 1 e 2 resumem a análise, mostrando os critérios que nortearam a avaliação e o desempenho de cada um dos sites. Nas tabelas usamos o "X" para ilustrar quando satisfaz o requisito e "-" para quando não satisfaz.

A não observação da taxonomia, provavelmente, onerará a empresa em custos que poderiam ser evitados. No entanto, o presente artigo ressalta o fato de que as questões de RNF presentes na taxonomia devem ser tratadas durante a fase de definição do sistema, e não posteriormente.

A aplicação do processo aqui apresentado, que usa heurís- ticas bem consolidadas da literatura de IHC (Interação Homem Computador), nas fases iniciais de definição do sistema deverá resultar num produto de melhor qualidade. Em um mercado cada vez mais competitivo, os RNF de usabilidade para aplicações de comércio eletrônico são de fundamental importância para o sucesso de um empreendimento.

A contribuição do presente trabalho, portanto, é a de ressaltar a importância dos RNF de usabilidade e fornecer um conjunto de características que devem ser levadas em consideração quando se está construindo aplicações comerciais. Os autores também acreditam que esse trabalho é um passo na direção de se desenvolver um campo de conhecimentos sobre RNF e de representar esse conhecimento através de um framework de RNF (CHUNG et al., 2000).

Tabela 1: Comparação dos Requisitos de Exibição da Informação nas duas Empresas.

\begin{tabular}{|l|c|c|}
\hline \multicolumn{1}{|c|}{ REQUISITOS } & INGRESSO.COM.BR & TICKETMASTER.COM.BR \\
\hline Consistência & $\mathrm{X}$ & - \\
\hline Projeto visual & $\mathrm{X}$ & $\mathrm{X}$ \\
\hline Comportamento inesperado & - & - \\
\hline Uso adequado de ícones & - & - \\
\hline Feedback & $\mathrm{X}$ & - \\
\hline Níveis de habilidade & $\mathrm{X}$ & $\mathrm{X}$ \\
\hline Recursos visuais & $\mathrm{X}$ & - \\
\hline Outras facilidades & $\mathrm{X}$ & - \\
\hline Percepção humana & $\mathrm{X}$ & - \\
\hline Uso apropriado da cor & $\mathrm{X}$ & - \\
\hline Metáforas & $\mathrm{X}$ & $\mathrm{X}$ \\
\hline Minimização da carga de memória & $\mathrm{X}$ & - \\
\hline Lei de Milller para menus & $\mathrm{X}$ & - \\
\hline Classificação funcional & $\mathrm{X}$ & - \\
\hline Manipulação direta & - & - \\
\hline Exibição apenas da informação essencial & - & \\
\hline Projeto Independente da Resolução & & \\
\hline
\end{tabular}

Tabela 2: Comparação dos Requisitos de Exibição da Informação nas duas Empresas.

\begin{tabular}{|c|c|c|}
\hline \multicolumn{1}{|c|}{ REQUISITOS } & INGRESSO.COM.BR & TICKETMASTER.COM.BR \\
\hline Mecanismos de ajuda & $\mathrm{X}$ & - \\
\hline Prevenção de erros & & - \\
\hline Inibição de itens & $\mathrm{X}$ & $\mathrm{X}$ \\
\hline Orient. para entrada correta de dados & $\mathrm{X}$ & $\mathrm{X}$ \\
\hline Minimização de entrada de dados & - & - \\
\hline Customização & $\mathrm{X}$ & - \\
\hline Recuperação de erros & & \\
\hline
\end{tabular}




\section{CONSIDERAC̣ÕES FINAIS}

No presente artigo, sites de duas empresas virtuais, "ingresso.com.br" e "ticketmaster.com.br.br", foram selecionados para que fosse conduzida uma análise de usabilidade, uma vez que o sucesso de tais empresas depende, em grande parte, de suas habilidades em estabelecer e manter uma comunicação com seus clientes. A análise revelou a empresa "ingresso.com.br" desenvolveu um site que, em vários aspectos, é mais fácil de ser usado do que o da empresa "ticketmaster.com.br". As interfaces do site "ingresso.com.br", em geral, são mais consistentes do que as da "ticketmaster. com.br" e exigem menos memorização desnecessária, mostrando-se de modo geral mais amigáveis no que diz respeito à entrada de dados. Um ponto interessante é que, apesar de ser uma empresa local e de pequeno porte, a Ingresso.com parece estar utilizando os requisitos não funcionais de forma mais adequada que a organização global "ticketmaster. com.br", facilitando não só a navegação, como também o uso do site por pessoas com diferentes níveis educacionais e culturais.

O uso de recursos visuais, como ícones, cores, imagens, quando bem planejados, facilita o reconhecimento e a memorização de características do site e pode também facilitar sua localização. Surpreendentemente, o site da "ticketmaster.com.br" usa tais elementos bem menos do que o da "ingresso.com.br". O "ticketmaster.com.br" faz mais uso de linguagem escrita e, em geral, demanda mais esforço de seus usuários. No mercado brasileiro, onde a educação é um fator crítico, isso pode contribuir para inibir seu sucesso e ajudar a "ingresso.com.br" a manter sua liderança. Esse resultado também sugere que companhias locais de países em desenvolvimento podem tirar vantagem do fato de que, devido ao nível educacional dos usuários, a usabilidade é, para eles, uma questão crucial, que pode estimular o desenvolvimento de melhores produtos, capazes de ajudá-los a enfrentar a concorrência de empresas globais.

\section{Artigo recebido em 15/06/2005 Aprovado para publicação em 01/06/2006}

\section{- Referências Bibliográficas}

ALBERTIN, A. L. Comércio Eletrônico-Modelos e Contribuições de sua Aplicação. 3.ed. São Paulo: Editora Atlas, , 1999.

ALBERTIN, A.L. O Comércio Eletrônico Evolui e Consolida-seno Mercado Brasileiro. São Paulo: Published in Revista de Administração de Empresas, v. 40, n.4, p. 42-50, out./dez, 2000.

ALBERTIN, A. L. Valor Estratégico dos Projetos de Tecnologia de Informação. São Paulo: Published in Revista de Administração de Empresas, v. 41, n. 3, p. 42-50, jul./set., 2001.

APPLE COMPUTER, Inc. Macintosh Human Interface Guidelines - Addison-Weslwy Company, 1992.

BREITMAN, K. K.; LEITE J. C. S. P. The World's Stage: A Survey on Requirements Engineering Using a Real-Life Case-Study. Journal of the Brazilian Computer Society, $\mathrm{n}$. 1, v. 6, p. 13-37, jul., 1999.

BIAS, R.G.; MAYHEW, D.G. Cost-justifying usability. Academic Press, 1994.
CHUNG, L.; NIXON, B.; YU, E.; MYLOPOULOS, J. Non-Functional Require ments in Software Engineering. Kluwer Academic Publishers, 2000

COGBURN, D. L. HCI in the so-called developing world:what's in it for everyone. Interactions. v. 10, Winds of change Special Issue: HCI in the developing world, p. 80-87. mar./apr., 2003.

CYSNEIROS, L. M.; LEITE, J. C. S. P. Integrating Non-Functional Requirements into data model. $4^{\text {th }}$ International Symposium on Requirements Engineering. Ireland June, 1999.

Davis, A. "Software Requirements: Objects Functions and States" - Prentice Hall, 1993.

FERREIRA, S. B. L.; LEITE, J. C. S. P. Sistemas de Informação Globalizados: Desafios Culturais - Proceedings of the XXVII ENAMPAD. Curitiba, Paraná, 2004.

FERREIRA, S. B. L.; LEITE, J. C. S. P. Avaliação da usabilidade em sistemas de informação: o caso do sistema submarino". Proceedings published in the journal Revista de Administração Contemporânea-RAC. Publicação quadrimestral da ANPAD - Associação dos Programas de Pós Graduação em Adminstração, v. 7, n. 2, p. 115-137, abr.jun. 2003.

FERREIRA, S. B. L.; LEITE, J. C. S. P. Usability Oriented Information Systems - Proceedings of the annual conference BALAS - Business Association in Latin American Studies. Tampa, EUA, mar., 2002.

FOLEY, J. D.; DAM, A. V.; FEINER, S. K. \& HUGHES, J. F. Computer Graphics - Principles and Practice. Addison-Wesley Publishing Company, Second Edition, 1997.

JACKSON, R.; MACDONALD L.; FREEMAN K. Computer Generated Color: A Practical Guide to Presentation and Display. John Wiley \& Sons, 1994.

JOKELA, T. When good things happen to bad products:where are the benefits of usability in the consumer appliance market? Interactions, v. 11 , n. 6, p. 28-35, nov./dec., 2004.

LAUREL, B. Art of Human-Computer Interface Design. Massachusetts: AddisonWesley, 1990.
LEITE, J. C. S. P. Engenharia de Requisitos - Class Notes. "Engenharia de Requisitos. Depto. de Informática da Pontifícia Universidade Católica do Rio de Janeiro, 2004.

MARCUS, A. Color: A Tool for Computer graphics Communication. Color in Computer Graphics, n. 24, SIGGRAPH, 1987.

MARCUS, A. Metaphor design in user interfaces. ACM SIGDOC Asterisk Journal of Computer Documentation, v. 22, n. 2, p. 43-57, maio, 1998.

NIELSEN, J.; TAHIR, M. Homepage: Usabilidade - 50 Websites desconstruídos. Rio de Janeiro: Editora Campus, 2002.

NIELSEN, J. Designing Web Usability. Indianopolis: News Riders Publishing, 2000.

NORMAN, D. A. The Invisible Computer: why good products can fall, the personal computer is so complex, and information appliances are the solution. Massachusets: MIT Press, 1999.

NORMAN, D. A. User Centered Systems Design. Lawrance Earlbaum Associates, 1986. 
- Referências Bibliográficas

O 'BRIEN, J. A. Sistemas de Informação e as decisões Gerenciais na era da Internet". Rio de Janeiro: Saraiva, 2001.

PEARROW, M. Web Site Usability Handbook. Massachusetts: Charles River Media, 2000.

PRESSMAN, R. S. Software Engineering - A Practioner's Approach. Sixth edition., McGraw-Hill, Inc, 2004.
SEFFAH, A.; METZKER, E. The obstacles and myths of usability and software engineering. Communications of the ACM, v. 47, n. 12, p. 71-76, dec., 2004.

SHNEIDERMAN, B. Designing the User Interface - Strategies for Effective Human-Computer Interaction. Massachusetts: Addison-Wesley, 1997.

SMITH, W. Computer Color: Psychophysics, Task Application and Asthetics.
Color in Computer Graphics, n. 24, SIGGRAPH, 1987.

SOMMERVILLE, I. Software Engineering (7th ed). Harlow: Addison-Wesley, 2004.

SOMMERVILLE, I.; SAWER, P. Requirements Engineering: A Good Practice Guide. England: John Wiley \& Sons, 1997.

TOGNAZZINI, B. Tog on Software Desig. Massachusetts: Addison-Wesley,1995. (http_1) - 10/2/2005 - http://www.oslo. sintef.no/avd/32/3270/brosjyrer/engelsk/index.html

(http_2) - ingresso.com.br - 26/3/2004 - www.ingresso.com.br

(http_3)-ticketmaster.com.br-27/3/2005 - http://www.ticketmaster.com.br/

(http_4) - 23/12/2005 - http://ucsnews. ucs.br/forumgc/rolando/tsld002.htm

\section{- Sobre os autores}

\section{Simone Bacellar Leal Ferreira}

Universidade Federal do Estado do Rio de Janeiro - UNIRIO

Professora adjunta do Departamento de Informática Aplicada

End.: Av. Pasteur, 458, Urca - 22290-240

Tel.: 55 (21) 2244-5613

E-mail: simone@uniriotec.br

\section{Marie Agnes Chauvel}

IAG PUC Rio

Professora Adjunta

End.: Av. Padre Lenoel Franca s/n., Gávea - Rio de Janeiro

Tel.: 55 (21) 314-1895

E-mail: Marie@iag.puc-rio.br

\section{Denis Silva da Silveira}

IBMEC - Faculdades Ibmec-RJ - Mestrado e Graduação em Administração

Mestre e Doutorando em Engenharia de Produção da COPPE\UFRJ

Professor Assistente

End.: Av. Rio Branco, n. 108 9o andar - Centro - Rio de Janeiro - 20040-001

Tel.: 55 (21) 4503-4187

E-mail: denis@ibmecrj.bre denis@pep.ufrj.br 